\title{
The second ESGAR consensus statement on CT colonography
}

\author{
Emanuele Neri • Steve Halligan • Mikael Hellström • \\ Philippe Lefere • Thomas Mang • Daniele Regge • \\ Jaap Stoker • Stuart Taylor • Andrea Laghi • \\ ESGAR CT Colonography Working Group
}

Received: 25 December 2011 /Revised: 18 March 2012 / Accepted: 1 April 2012 /Published online: 15 September 2012

(C) The Author(s) 2012. This article is published with open access at Springerlink.com

\begin{abstract}
Objective To update quality standards for CT colonography based on consensus among opinion leaders within the European Society of Gastrointestinal and Abdominal Radiology (ESGAR).

Material and methods A multinational European panel of nine members of the ESGAR CT colonography Working Group (representing six EU countries) used a modified Delphi process to rate their level of agreement on a variety of statements pertaining to the acquisition, interpretation and implementation of CT colonography. Four Delphi rounds were conducted, each at 2 months interval.

Results The panel elaborated 86 statements.
\end{abstract}

\section{E. Neri $(\bowtie)$}

Diagnostic and Interventional Radiology,

University of Pisa,

Pisa, Italy

e-mail: emanuele.neri@med.unipi.it

\section{S. Halligan}

University College London, Centre for Medical Imaging,

University College Hospital,

London, UK

\section{Hellström}

Department of Radiology, Sahlgrenska University Hospital and

Sahlgrenska Academy at University of Gothenburg,

Gothenburg, Sweden

\section{P. Lefere}

Virtual Colonoscopy Teaching Centre,

Hooglede, Belgium

\section{T. Mang}

Department of Radiology, Medical University of Vienna,

Vienna, Austria

\section{Regge}

Institute for Cancer Research and Treatment,

Candiolo-Torino, Italy
In the final round the panelists achieved complete consensus in 71 of 86 statements ( $82 \%$ ). Categories including the highest proportion of statements with excellent Cronbach's internal reliability were colon distension, scan parameters, use of intravenous contrast agents, general guidelines on patient preparation, role of $\mathrm{CAD}$ and lesion measurement.

Lower internal reliability was achieved for the use of a rectal tube, spasmolytics, decubitus positioning and number of CT data acquisitions, faecal tagging, $2 \mathrm{D}$ vs. $3 \mathrm{D}$ reading, and reporting. Conclusion The recommendations of the consensus should be useful for both the radiologist who is starting a CTC service and for those who have already implemented the technique but whose practice may need updating.

\section{J. Stoker}

Department of Radiology,

Academic Medical Center,

University of Amsterdam,

Amsterdam, NL, The Netherlands

S. Taylor

Department of Medical Imaging,

University College London,

London, UK

\author{
A. Laghi \\ Department of Radiological Sciences, \\ Oncology and Pathology, \\ Sapienza - Università di Roma, \\ Rome, Italy
}

ESGAR CT Colonography Working Group

Department of Translational Research, and Advanced

Technologies in Medicine and Surgery, University of Pisa,

Nuovo Ospedale S. Chiara, UO Radiodiagnostica 1,

Via Paradisa 2,

56100 Pisa, Italy 
Key Points

- Computed tomographic colonography is the optimal radiological method of assessing the colon

- This article reviews ESGAR quality standards for CT colonography

- This article is aimed to provide CT-colonography guidelines for practising radiologists

- The recommendations should help radiologists who are starting/updating their CTC services

Keywords CT colonography · Guidelines · Computed tomography $\cdot$ Colon $\cdot$ Polyps

\section{Introduction}

Since its introduction (in 1994) [1], clinical implementation of computed tomography (CT) colonography has been governed by advances in CT technology, improvements in dedicated analysis software, development of patient preparation regimens and local diagnostic policies.

In 2007 the European Society of Gastrointestinal and Abdominal Radiology (ESGAR) consensus statement on CT colonography was published, detailing how best to conduct and interpret the examination [2]. That document was based on collective experience up to the beginning of 2006, and the authors represented the EU countries in which CTC underwent consistent clinical implementation (UK, Italy, Belgium and The Netherlands). Over the last 5 years expansion of the CT colonography literature has continued and several important studies, including multicentre studies, have been published [3-5]. These new data have provided further insight regarding optimisation of the CT colonography technique, interpretation and diagnostic capabilities. Indeed CT colonography is now recommended for colorectal cancer screening by several international groupings and is widely used to investigate patients with symptoms suggestive of colorectal cancer $[6,7]$. Although recent review articles provide some guidance regarding the optimal CT colonography technique, given the evolving data [8-11] there is a current need to update the ESGAR consensus document.

The purpose of this article is therefore to update quality standards for CT colonography based on examination of the existing literature and expert opinion from key opinionleaders within the European Society of Gastrointestinal and Abdominal Radiology.

\section{Materials and methods}

Consensus panel

A multinational European panel of nine members of the ESGAR CTC Working Group (comprising J.S., S.H., S.T.,
P.L., T.M., D.R., M.H., A.L., E.N., and representing six EU countries: Austria, Belgium, Italy, The Netherlands, Sweden and the UK) used a modified Delphi process $[12,13]$. The Delphi process consists of a survey conducted in two or more rounds; the answers (or statements) collected in the first survey are modified in the second, the third, etc., to reach the maximum consensus among the experts. We rated the level of agreement among the experts on a variety of statements pertaining to the acquisition, interpretation and implementation of CT colonography. Four Delphi rounds were conducted, each at 2 months interval.

One of the panellists was chosen as the facilitator (E.N.).

In the first round the facilitator emailed a questionnaire with 22 items pertaining to panel members' personal approaches to $\mathrm{CTC}$, including items on patient preparation, data acquisition technique, image interpretation and clinical implementation (Table 1). Responses collected from all panellists were merged into a unique datasheet that served to identify areas of agreement and conflict in panellist opinion.

In the second round, the panellists attended a 1-day, faceto-face meeting, and, on the basis of their main areas of research and expertise, were divided into four working groups (WG) as follows: bowel preparation and tagging (WG 1), insufflation and scanning protocols (WG 2), reading paradigm (WG 3) and reporting (WG 4). Each WG independently drafted a cluster of statements pertaining to their allocated subject (Table 2). Each statement was built on the basis of panelists' expertise and available indexed literature. Each WG then presented their proposed statements to the whole panel for consideration and subsequent discussion, during which time the content and wording of statements were modified until a general consensus emerged.

In the third and fourth rounds, copies of the latest statements were sent by email to panellists, who then indicated independently their level of agreement with each individual statement using a 5-point scale, as follows: 1, strongly disagree with the statement; 2 , disagree somewhat with the statement; 3, undecided; 4, agree somewhat with the statement; 5, strongly agree with the statement.

After the third round the facilitator collected panellists' ratings and determined the agreement score for each statement. If the mean score for an individual item was lower than four (maximum possible=five) the facilitator asked panelists to review the statement and attempt to reach a consensus in the fourth round.

Statistical analysis

To measure the internal consistency of panellist's ratings for each statement, a quality analysis was performed using Cronbach's $\alpha$ correlation coefficient and SPSS (SPSS, Chicago, Ill.) [14]. Cronbach's $\alpha$ was determined after each round. 
Table 1 Second ESGAR CT colonography consensus. Survey of the first Delphi round

Please rate your suggestions as follows (in some questions)

$\square 1 \square 2 \quad \square 3 \quad \square 4$
Do not suggest
Could suggest if no other choice
Regularly suggest
Strongly suggest

Preparation and tagging. Which would you suggest? $\square$ Cathartic and no tagging $\square$ Cathartic and fecal tagging $\square$ Reduced laxative and fecal tagging $\square$ No laxative and fecal tagging

Cleansing and tagging agents: $\square$ PEG / MACROGOL $\square$ Phosphosoda $\square$ Gastrografin $\square$ Barium alone $\square$ lodine alone

$\square$ Barium and iodine

Cleansing regimen (when to start) (1-4)

$\square 1$ day before exam $\square 2$ days before exam $\square 3$ days before exam

Tagging regimen (when to start) (1-4)

$\square$ Same day of the exam $\square 1$ day before exam $\square 2$ days before exam $\square 3$ days before exam Insufflation and scanning protocol

Which distension agent? $\quad \square$ Air $\square \mathrm{CO} 2$

Who should perform the insufflation? $\quad \square$ Medical doctor $\square$ Radiographer $\square$ Nurse

In which situations you would suggest the use of spasmolytics? (check all that apply):

$\square$ regularly, in all patients $\square$ in patients where at scout view the colon appears poorly distended

$\square$ if patient is finding insufflation unduly uncomfortable $\square$ other known diverticular disease $\quad \square$ not used

Which spasmolytics (1-4) $\square$ Buscopan $\square$ Glucagon

Which rectal tube (1-4) $\square$ Flexible with balloon $\square$ Flexible without balloon $\square$ Rigid with balloon $\square$ Rigid without balloon

CT scanner type (minimum number of rows) $\square$ 1-2 $\square 4 \square 8 \square 16 \square 32 \square 64 \square$ more rows

CT Low dose protocol: $\square$ never use $\square$ use only in asymptomatic patients $\square$ to use in both asymptomatic and symptomatic patients

CT Normal dose protocol: $\square$ never use $\square$ use only in symptomatic patients $\quad \square$ to use in both asymptomatic and symptomatic patients

Intravenous contrast: $\square$ not used $\square$ used in all symptomatic patients $\square$ used in patients with known cancer or suspected after first series acquisition $\square$ always used

Decubitus (1-4): $\square$ Supine first and after prone $\square$ Prone first and after supine $\square$ Additional lateral decubitus Who could read and report the exam?

$\square$ Radiologist alone $\quad \square$ Radiographer alone $\quad \square$ By radiographer (preliminary read) then by radiologist (verification) $\quad \square$ By resident (preliminary read) then by radiologist (verification) $\square$ Other (gastroenterologist)

Which is your preferred reading paradigm?

$\square$ primary 2D + 3D as problem solving $\quad \square$ primary 3D $+2 D$ as problem solving $\square$ virtual dissection

Which is your preferred CAD reading paradigm? $\square 2^{\text {nd }}$ reader $\quad \square 1^{\text {st }}$ reader $\square$ concurrent reading

Who should write the report? $\square$ radiologist $\square$ radiographer $\square$ other (gastroenterologist, etc...)

Do you follow C-RADS (CT Colonography Reporting and Data System) recommendations?

$\square$ yes $\square$ no $\square$ in some occasions (please specify)

When a $<6 \mathrm{~mm}$ polyp is detected at CTC, what is your suggested policy?

$\square$ never report $\square$ report only in symptomatic or high risk patients $\quad \square$ report it, but don't advise a polypectomy

$\square$ report it, and advise a polypectomy $\quad \square$ report it, and advise a follow up

When a 6-9 $\mathrm{mm}$ polyp is detected at СTC, what is your suggested policy?

$\square$ never report $\square$ report only in symptomatic or high risk patients $\quad \square$ report but don't advise a polypectomy

$\square$ report and advise a polypectomy $\quad \square$ report and advise a follow up

Informed consent should be obtained? $\square$ yes $\square$ no 
Table 2 Statements elaborated by the panellists in the second Delphi round, and discussed in the third and fourth to reach the maximum consensus and Cronbach's internal reliability. Statements with score between 4 and 5 are highlighted to show the situations in which all panellists agreed on the statement but the level of support differed (i.e.

"agree somewhat" versus "agree strongly")

\begin{tabular}{|c|c|c|c|c|c|c|c|c|}
\hline & & Second round & $\begin{array}{l}\text { Third } \\
\text { round }\end{array}$ & & & $\begin{array}{l}\text { Fourth } \\
\text { round }\end{array}$ & & \\
\hline Cluster & $\begin{array}{l}\text { Stat. } \\
\#\end{array}$ & Statements & $\begin{array}{l}\text { mean } \\
\text { scores }\end{array}$ & $\begin{array}{l}\text { std } \\
\text { dev }\end{array}$ & $\begin{array}{l}\text { Cronbach's } \\
\text { alpha }\end{array}$ & $\begin{array}{l}\text { mean } \\
\text { scores }\end{array}$ & $\begin{array}{l}\text { std } \\
\text { dev }\end{array}$ & $\begin{array}{l}\text { Cronbach's } \\
\text { alpha }\end{array}$ \\
\hline \multirow[t]{4}{*}{ Rectal tube } & 1 & $\begin{array}{l}\text { The use of thin and flexible rectal tubes is recommended (1). Rigid catheters } \\
\text { should not be used. Inflation of a small balloon with air is optional. }\end{array}$ & 5.00 & .000 & 0,074 & 5.00 & .000 & 0,53 \\
\hline & 2 & $\begin{array}{l}\text { If an inflated rectal catheter balloon is used, it should be deflated in one scan } \\
\text { acquisition to reduce the risk of masking a distal lesion. }\end{array}$ & 4.78 & .441 & & 5.00 & .000 & \\
\hline & 3 & $\begin{array}{l}\text { Placement of the rectal tube must be performed by a practitioner specifically } \\
\text { trained in the technique. This may be a radiologist, resident, radiographic } \\
\text { technician or radiographic nurse, depending on local practice. }\end{array}$ & 5.00 & .000 & & 5.00 & .000 & \\
\hline & 4 & $\begin{array}{l}\text { A digital rectal examination is not mandatory. If inflation of a rectal balloon is } \\
\text { performed consideration should be given to digital rectal examination. }\end{array}$ & 4.56 & .527 & & 4.56 & .527 & \\
\hline \multirow[t]{4}{*}{ Spasmolytics } & 5 & $\begin{array}{l}\text { Use of Spasmolytics (Hyoscin-N-Buthylbromide (Buscopan } 囚) \text { ) is preferable prior } \\
\text { colonic distension, noting specific contraindications. However, decision to } \\
\text { administer spasmolytics should be also based on patient's history (diverticular } \\
\text { disease, previous incomplete colonoscopy for strictures, etc). }\end{array}$ & 4.78 & .667 & 0,124 & 4.78 & .667 & 0,25 \\
\hline & 6 & Hyoscine-N-butylbromide (buscopan) is the spasmoltyic of choice. & 5.00 & .000 & & 5.00 & .000 & \\
\hline & 7 & $\begin{array}{l}\text { If spasmolytics are used, administration should be before commencing } \\
\text { insufflation. }\end{array}$ & 4.89 & .333 & & 4.89 & .333 & \\
\hline & 8 & If buscopan is contraindicated Glucagon ( $1 \mathrm{mg}$ ) may be used. & 4.56 & .726 & & 4.67 & .500 & \\
\hline $\begin{array}{l}\text { Colon } \\
\text { distension }\end{array}$ & 9 & $\begin{array}{l}\text { Automatic distension with } \mathrm{CO} 2 \text { is the method of choice, to optimize colonic } \\
\text { distension and to maximise patient comfort }\end{array}$ & 5.00 & .000 & 1 & 5.00 & .000 & 1 \\
\hline \multirow[t]{2}{*}{$\begin{array}{l}\text { Method of colon } \\
\text { distension }\end{array}$} & 10 & $\begin{array}{l}\text { Manual distension with carbon dioxide or room air is an acceptable alternative if } \\
\text { automated insufflations facilities are not available. }\end{array}$ & 5.00 & .000 & & 5.00 & .000 & \\
\hline & 11 & $\begin{array}{l}\text { Colonic insufflation must be performed by a practitioner specifically trained in } \\
\text { the technique. This may be a radiologist, resident, radiographic technician or } \\
\text { radiographic nurse, depending on local practice }\end{array}$ & 5.00 & .000 & & 5.00 & .000 & \\
\hline \multirow[t]{4}{*}{$\begin{array}{l}\text { Quality of } \\
\text { colonic } \\
\text { distension }\end{array}$} & 12 & $\begin{array}{l}\text { Colonic distension should be sufficient such that all segments are fully } \\
\text { visualized in at least one patient position and ideally in both. }\end{array}$ & 5.00 & .000 & 1 & 5.00 & .000 & 1 \\
\hline & 13 & The volume of gas administered does not alone indicate adequate distension. & 5.00 & .000 & & 5.00 & .000 & \\
\hline & 14 & $\begin{array}{l}\text { The optimum insufflated gas volume differs between individuals and should be } \\
\text { judged taking into consideration colonic pressure (if measured), patient } \\
\text { tolerance and the appearance on the scout image. }\end{array}$ & 5.00 & .000 & & 5.00 & .000 & \\
\hline & 15 & $\begin{array}{l}\text { The degree and completeness of colonic distension should be checked by } \\
\text { inspection of a scout image acquired in both patient positions prior to each full } \\
\text { CT data acquisition. }\end{array}$ & 5.00 & .000 & & 5.00 & .000 & \\
\hline $\begin{array}{l}\text { Image } \\
\text { acquisition }\end{array}$ & 16 & A combination of supine and prone positioning is standard. & 5.00 & .000 & & 5.00 & .000 & \\
\hline \multirow[t]{3}{*}{$\begin{array}{l}\text { Decubitus and } \\
\text { number of } C T \\
\text { scans }\end{array}$} & 17 & $\begin{array}{l}\text { If the patient is unable to lie in the prone position, a lateral decubitus scan is } \\
\text { recommended. }\end{array}$ & 5.00 & .000 & N/A & 5.00 & .000 & 0,3 \\
\hline & 18 & $\begin{array}{l}\text { If segments are inadequately visualized due to poor distension, an additional } \\
\text { scan is indicated with further insufflation and/or in a different position. }\end{array}$ & 4.78 & .441 & & 5.00 & .000 & \\
\hline & 19 & $\begin{array}{l}\text { There is little evidence that the order of patient positioning (ie supine or prone } \\
\text { position first) influences distension quality. }\end{array}$ & 5.00 & .000 & & 5.00 & .000 & \\
\hline \multirow[t]{8}{*}{$\begin{array}{l}\text { Scan } \\
\text { parameters }\end{array}$} & 20 & $\begin{array}{l}\text { Use of multidetector row CT scanners }(=\text { and }>4 \text { rows) is a prerequisite for CTC } \\
\text { given the requirement to achieve a CT scan of the whole abdomen with a } \\
\text { narrow collimation within one breath-hold. }\end{array}$ & 5.00 & .000 & 1 & 5.00 & .000 & 1 \\
\hline & 21 & $\begin{array}{l}\text { Maximum collimation influences colonic lesion detection and should be no more } \\
\text { than } 2.5 \mathrm{~mm} \text {, although newer generation CT-Scanners allow routine acquisition } \\
\text { of thinner slices which is preferable. }\end{array}$ & 5.00 & .000 & & 5.00 & .000 & \\
\hline & 22 & Images should be reconstructed with an overlap. ( $20-30 \%$ overlap). & 5.00 & .000 & & 5.00 & .000 & \\
\hline & 23 & $\begin{array}{l}\text { CT scans should be performed in cranio-caudal direction to minimize breathing } \\
\text { artifacts. }\end{array}$ & 5.00 & .000 & & 5.00 & .000 & \\
\hline & 24 & $\begin{array}{l}\text { Low radiation dose protocols without IV contrast should be used for screening } \\
\text { CTC. }\end{array}$ & 5.00 & .000 & & 5.00 & .000 & \\
\hline & 25 & $\begin{array}{l}120 \mathrm{kV} \text { should be used for both supine and prone acquisitions, but lower kV } \\
\text { may be acceptable in specific situations. }\end{array}$ & 5.00 & .000 & & 5.00 & .000 & \\
\hline & 26 & $\begin{array}{l}\text { When IV contrast is not adminstered } \leq 50 \mathrm{mAs} \text { is preferable for prone and } \\
\text { supine positions, excepting overweight patients. }\end{array}$ & 5.00 & .000 & & 5.00 & .000 & \\
\hline & 27 & Dose modulation and iterative reconstruction should be applied if available. & 5.00 & .000 & & 5.00 & .000 & \\
\hline
\end{tabular}


Table 2 (continued)

\begin{tabular}{|c|c|c|c|c|c|c|c|c|}
\hline \multirow[t]{6}{*}{ IV Contrast } & 28 & $\begin{array}{l}\text { IV contrast is not required for colonic evaluation but improves evaluation of } \\
\text { extra-colonic organs. }\end{array}$ & 4.89 & .333 & 0,38 & 5.00 & .000 & 1 \\
\hline & 29 & Oral tagging agents do not preclude the use of IV contrast. & 5.00 & .000 & & 5.00 & .000 & \\
\hline & 30 & $\begin{array}{l}\text { IV contrast should be administered in all patients with known colorectal cancer } \\
\text { (unless contraindicated) to facilitate staging. }\end{array}$ & 5.00 & .000 & & 5.00 & .000 & \\
\hline & 31 & $\begin{array}{l}\text { In symptomatic patients without known colorectal cancer, routine administration } \\
\text { of IV contrast depends on the clinical indication and requirement to fully } \\
\text { evaluate the extracolonic organs, especially if an abnormality has been seen on } \\
\text { the unenhanced scan. }\end{array}$ & 5.00 & .000 & & 5.00 & .000 & \\
\hline & 32 & If IV contrast is administered, acquisition should be in the portal venous phase. & 4.89 & .333 & & 5.00 & .000 & \\
\hline & 33 & $\begin{array}{l}\text { If IV contrast is administered a standard radiation dose protocol should be } \\
\text { applied, although a reduced } \mathrm{mA} \text { acquisition } \leq 50 \mathrm{mAs} \text { should be utilized during } \\
\text { the unenhanced acquisition }\end{array}$ & 5.00 & .000 & & 5.00 & .000 & \\
\hline \multirow{3}{*}{$\begin{array}{l}\text { Precautions } \\
\text { before and after } \\
\text { CT scan }\end{array}$} & 34 & $\begin{array}{l}\text { If intravenous contrast media is administered, it is preferable to do so in the } \\
\text { supine position }\end{array}$ & 4.89 & .333 & & 4.89 & .333 & \\
\hline & 35 & $\begin{array}{l}\text { Before the patient leaves the CT table, the quality of the examination should } \\
\text { ideally be assessed by a practitioner specifically trained in the technique. } \\
\text { Specific attention should also be made for the presence of perforation. }\end{array}$ & 4.89 & .333 & 0,75 & 4.89 & .333 & 0,75 \\
\hline & 36 & $\begin{array}{l}\text { If colonic perforation is a possibility, for example following difficult optical } \\
\text { colonoscopy, this should be excluded via acquisition of "low dose" abdominal } \\
\text { CT, before starting CTC. }\end{array}$ & 4.89 & .333 & & 4.89 & .333 & \\
\hline & 37 & $\begin{array}{l}\text { If polypectomy has recently been performed there is a case for delaying CTC } \\
\text { depending on the type of biopsy. There is no clear evidence regarding the } \\
\text { interval. }\end{array}$ & 5.00 & .000 & & 5.00 & .000 & \\
\hline $\begin{array}{l}\text { Patient } \\
\text { preparation }\end{array}$ & 38 & $\begin{array}{l}\text { General patient preparation for CTC is mandatory for proper detection of polyps } \\
\text { and CRC in both symptomatic and asymptomatic individual. This may include } \\
\text { dietary restriction, oral contrast agent and bowel purgation. }\end{array}$ & 5.00 & .000 & 1 & 5.00 & .000 & 1 \\
\hline \multirow[t]{2}{*}{$\begin{array}{l}\text { General } \\
\text { guidelines }\end{array}$} & 39 & $\begin{array}{l}\text { The general patient preparation scheme, including bowel purgation if used, } \\
\text { should be straightforward and simple. }\end{array}$ & 5.00 & .000 & & 5.00 & .000 & \\
\hline & 40 & $\begin{array}{l}\text { An information leaflet with detailed description of the preparation scheme is } \\
\text { advised. }\end{array}$ & 5.00 & .000 & & 5.00 & .000 & \\
\hline \multirow[t]{10}{*}{$\begin{array}{l}\text { Aggressivenes } \\
\text { of preparation }\end{array}$} & 41 & Tagging regimens should be restricted to no more than 24 hours. & 4.67 & .707 & 0,57 & 4.78 & .667 & 0,6 \\
\hline & 42 & Aggressive catharsis (purgation) should be restricted to 24 hours or less. & 5.00 & .000 & & 5.00 & .000 & \\
\hline & 43 & $\begin{array}{l}\text { Bowel preparation should include dietary restrictions (e.g. Low fibre diet), to } \\
\text { reduce faecal volume and faecal heterogeneity. }\end{array}$ & 5.00 & .000 & & 5.00 & .000 & \\
\hline & 44 & The bowel preparation for CTC should normally include laxative agents. & 5.00 & .000 & & 5.00 & .000 & \\
\hline & 45 & $\begin{array}{l}\text { A trade-off between the patient burden and the required image quality to detect } \\
\text { the target lesion should be considered when choosing a laxative agent. }\end{array}$ & 5.00 & .000 & & 5.00 & .000 & \\
\hline & 46 & $\begin{array}{l}\text { CTC without laxative, but with tagging, may be considered in frail and elderly } \\
\text { patients where CRC is the diagnostic target. }\end{array}$ & 5.00 & .000 & & 5.00 & .000 & \\
\hline & 47 & $\begin{array}{l}\text { Sodium phosphate is efficient but not recommended at double dose since this } \\
\text { may cause serum electrolyte disturbances, phosphate nephropathy. }\end{array}$ & 4.67 & 1.000 & & 4.67 & 1.000 & \\
\hline & 48 & $\begin{array}{l}\text { Magnesium citrate has less side effects and should therefore be preferred over } \\
\text { sodium phosphate. However it has restricted availability in Europe. }\end{array}$ & 4.67 & 1.000 & & 4.67 & 1.000 & \\
\hline & 49 & $\begin{array}{l}\text { Polyethylene glycol preparations avoid many electrolyte disturbances, but may } \\
\text { result in excess colonic fluid. }\end{array}$ & 4.89 & .333 & & 4.89 & .333 & \\
\hline & 50 & $\begin{array}{l}\text { lodinated contrast media are used for tagging and also may have a laxative } \\
\text { effect. }\end{array}$ & 5.00 & .000 & & 5.00 & .000 & \\
\hline \multirow[t]{9}{*}{$\begin{array}{l}\text { Faecal } \\
\text { tagging }\end{array}$} & 51 & Faecal tagging is mandatory. & 4.89 & .333 & 0,378 & 5.00 & .000 & 0,4 \\
\hline & 52 & Faecal tagging can be achieved with either iodine or barium or both. & 4.78 & .667 & & 5.00 & .000 & \\
\hline & 53 & Insufficient scientific evidence exists to favour one tagging agent over the other. & 4.33 & 1.118 & & 4.78 & .441 & \\
\hline & 54 & lodine results in homogeneous tagging which may facilitates interpretation. & 5.00 & .000 & & 5.00 & .000 & \\
\hline & 55 & $\begin{array}{l}\text { Hyperosmolar iodine based preparations have a laxative effect, which should be } \\
\text { taken into account. }\end{array}$ & 5.00 & .000 & & 5.00 & .000 & \\
\hline & 56 & $\begin{array}{l}\text { Caution is necessary when prescribing iodine-based preparations in cases of } \\
\text { known iodine-contrast medium allergy. }\end{array}$ & 5.00 & .000 & & 5.00 & .000 & \\
\hline & 57 & $\begin{array}{l}\text { Barium is inert and consequently has no cathartic effect but may cause } \\
\text { constipation. }\end{array}$ & 5.00 & .000 & & 5.00 & .000 & \\
\hline & 58 & Barium may produce heterogeneous tagging of stool and fluid. & 5.00 & .000 & & 5.00 & .000 & \\
\hline & 59 & Barium suspensions may impair same-day colonoscopy. & 5.00 & .000 & & 5.00 & .000 & \\
\hline
\end{tabular}


Table 2 (continued)

\begin{tabular}{|c|c|c|c|c|c|c|c|c|}
\hline & 60 & $\begin{array}{l}\text { Barium AND iodine combine stool and fluid tagging which may be desirable, but } \\
\text { this more complex preparation scheme may reduce patient compliance. }\end{array}$ & 5.00 & .000 & & 5.00 & .000 & \\
\hline & 61 & $\begin{array}{l}\text { There is a wide variability in patient preparation schemes between experienced } \\
\text { centres. }\end{array}$ & 5.00 & .000 & & 5.00 & .000 & \\
\hline $\begin{array}{l}\text { Reading } \\
\text { paradigm }\end{array}$ & 62 & $\begin{array}{l}\text { Interpretation of CT colonography should incorporate both 2D and 3D } \\
\text { visualization (i.e. fly-through). }\end{array}$ & 4.89 & .333 & N/A & 4.89 & .333 & N/A \\
\hline \multirow[t]{3}{*}{$\begin{array}{l}2 D \text { and } 3 D \\
\text { reading }\end{array}$} & 63 & $\begin{array}{l}\text { Initial interpretation using either primary } 2 \mathrm{D} \text { or primary } 3 \mathrm{D} \text { methods are } \\
\text { acceptable depending on personal preference and on WS availability. }\end{array}$ & 5.00 & .000 & & 5.00 & .000 & \\
\hline & 64 & On average the primary $2 \mathrm{D}$ interpretation is likely to be faster. & 5.00 & .000 & & 5.00 & .000 & \\
\hline & 65 & $\begin{array}{l}\text { Other 3D visualization options (e.g. virtual dissection, panoramic view, filet view, } \\
\text { ecc) are viable alternatives provided that the reader is fully trained in } \\
\text { conventional } 2 \mathrm{D} \text { and } 3 \mathrm{D} \text { visualisation displays, and is aware that other data } \\
\text { display may introduce distortion. }\end{array}$ & 5.00 & .000 & & 5.00 & .000 & \\
\hline \multirow[t]{6}{*}{$C A D$} & 66 & $\begin{array}{l}\text { 2nd read CAD is recommended because it increases sensitivity for polyp } \\
\text { detection without an unacceptable decrease in specificity. }\end{array}$ & 5.00 & .000 & 1 & 5.00 & .000 & 1 \\
\hline & 67 & $\begin{array}{l}\text { Readers should be aware that it is possible to reject true positive CAD prompts } \\
\text { in error. }\end{array}$ & 5.00 & .000 & & 5.00 & .000 & \\
\hline & 68 & $\begin{array}{l}\text { CAD should be adopted by radiologists only after they have been adequately } \\
\text { trained in unassisted interpretation of CT colonography and the use of CAD. }\end{array}$ & 5.00 & .000 & & 5.00 & .000 & \\
\hline & 69 & $\begin{array}{l}\text { CAD is an adjunct to unassisted interpretation and its implementation will } \\
\text { depend on local factors including costs, personal preference and algorithm } \\
\text { and/or WS availability. }\end{array}$ & 5.00 & .000 & & 5.00 & .000 & \\
\hline & 70 & $\begin{array}{l}\text { CAD is less likely to be useful in situations were there are multiple false positive } \\
\text { prompts, for example a poorly prepared colon. }\end{array}$ & 5.00 & .000 & & 5.00 & .000 & \\
\hline & 71 & $\begin{array}{l}\text { CAD algorithms have been developed primarily for polyp detection although } \\
\text { they may also detect cancer. }\end{array}$ & 5.00 & .000 & & 5.00 & .000 & \\
\hline \multirow[t]{4}{*}{$\begin{array}{l}\text { Lesion } \\
\text { measurement }\end{array}$} & 72 & $\begin{array}{l}\text { The maximal diameter of a lesion should be measured on the plane that best } \\
\text { demonstrates this dimension, excluding any stalk if present, and its segmental } \\
\text { location reported. }\end{array}$ & 5.00 & .000 & 1 & 5.00 & .000 & 1 \\
\hline & 73 & $\begin{array}{l}\text { Diameter may be estimated using } 2 \mathrm{D} \text { and or } 3 \mathrm{D} \text { methods but readers should be } \\
\text { aware that } 3 \mathrm{D} \text { estimates may occasionally be unreliable. }\end{array}$ & 5.00 & .000 & & 5.00 & .000 & \\
\hline & 74 & $\begin{array}{l}\text { Readers should be aware that there is frequent disagreement between CT and } \\
\text { the endoscopic measurements, and this may influence management when } \\
\text { patients are defined by polyp size categories. }\end{array}$ & 5.00 & .000 & & 5.00 & .000 & \\
\hline & 75 & $\begin{array}{l}\text { Readers should be aware that neither endoscopic nor CT estimates are wholly } \\
\text { accurate and both are affected by the way the measurement is made (e.g. CT } \\
\text { window level and width). Narrow windows should be avoided. }\end{array}$ & 5.00 & .000 & & 5.00 & .000 & \\
\hline \multirow[t]{4}{*}{ Flat lesions } & 76 & $\begin{array}{l}\text { The precise definition of a flat lesion is variable and controversial at the present } \\
\text { time. Lesion height above the surrounding mucosa should be reported when flat } \\
\text { lesions are encountered. An increasingly acceptable definition of a flat lesion on } \\
\text { CT colonography is one were the elevation of a lesion of } 6 \mathrm{~mm} \text { or larger above } \\
\text { the surrounding mucosa is } 3 \mathrm{~mm} \text { or less. }\end{array}$ & 4.89 & .333 & N/A & 5.00 & .000 & 1 \\
\hline & 77 & $\begin{array}{l}\text { Readers should be aware that CT colonography is less sensitive for flat lesions } \\
\text { than for other polyp morphologies. }\end{array}$ & 5.00 & .000 & & 5.00 & .000 & \\
\hline & 78 & $\begin{array}{l}\text { The likelihood of cancer increases in line with lesion diameter. There is no } \\
\text { exclusive threshold that defines cancer at CT colonography. When the } \\
\text { morphology of the lesion strongly suggests a cancer this terminology should be } \\
\text { used and alternatives such as "mass" should be avoided. }\end{array}$ & 5.00 & .000 & & 5.00 & .000 & \\
\hline & 79 & $\begin{array}{l}\text { Occasionally factors other than the maximal diameter of a single lesion may be } \\
\text { useful to indicate the clinical importance, for example fat attenuation which } \\
\text { indicates a lipoma. }\end{array}$ & 5.00 & .000 & & 5.00 & .000 & \\
\hline \multirow[t]{4}{*}{ Reporting } & 80 & $\begin{array}{l}\text { A report should include the Clinical information (under pinning the request } \\
\text { should be included in the report, along with personal and family history), the } \\
\text { Technical data (low or normal dose protocol, intravenous contrast) and, if } \\
\text { desired, preparation and tagging (laxative agent), tagging (tagging regimen), } \\
\text { insufflation (air or CO2), spasmolytics (used or not used), the effective dose in } \\
\text { mSv. }\end{array}$ & 4.44 & 1.014 & 0,4 & 4.44 & 1.014 & 0.4 \\
\hline & 81 & $\begin{array}{l}\text { The reported colonic findings should be: colonic anatomy (normal or abnormal.), } \\
\text { polyps and cancer (size, shape, maximum diameter, infiltration of the } \\
\text { extracolonic fat, location and other colonic (e.g. wall thickening, strictures, } \\
\text { diverticula, extrinsic compressions, post-surgical variations). }\end{array}$ & 5.00 & .000 & & 5.00 & .000 & \\
\hline & 82 & $\begin{array}{l}\text { The extracolonic organs should be interrogated and abnormalities reported, } \\
\text { noting the limitations if an unenhanced and or low dose technique was used. }\end{array}$ & 4.89 & .333 & & 4.89 & .333 & \\
\hline & 83 & $\begin{array}{l}\text { CT colonography should be reported by a radiologist, specifically trained in the } \\
\text { technique. }\end{array}$ & 5.00 & .000 & & 5.00 & .000 & \\
\hline
\end{tabular}


Table 2 (continued)

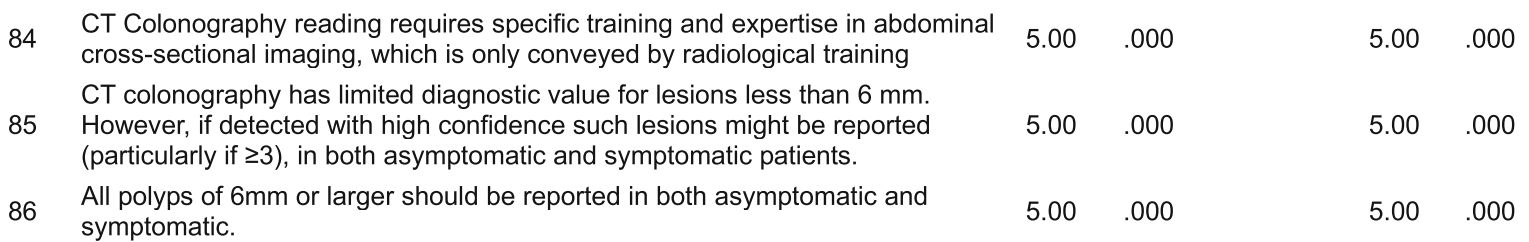

Cronbach's $\alpha$ reliability coefficient normally ranges between 0 and 1 . The closer the Cronbach's $\alpha$ coefficient is to 1.0 , the greater the internal consistency of the item. An $\alpha$ coefficient $>0.9$ was considered excellent, $\alpha>0.8$ good, $\alpha>0.7$ acceptable, $\alpha>0.6$ questionable, $\alpha>0.5$ poor and $\alpha<0.5$ unacceptable. For the iterations, an $\alpha$ of 0.8 was considered a reasonable goal for internal reliability. All panellist ratings for each statement were also analysed with descriptive statistics, estimating the mean, maximum and minimum score, and their standard deviation.

A mean score of 4 was considered to represent "good" agreement between panellists, a score of 5 "complete" agreement.

\section{Results}

Based on the questionnaire provided by the facilitator, the panel elaborated 86 statements that were collected by the facilitator and organised into nine groups, as follows: (1) rectal tube, (2) spasmolytics, (3) colon distension, (4) image acquisition, (5) patient preparation, (6) faecal tagging, (7) reading paradigm, (8) lesion measurement and (9) reporting (Table 2).

In the third round the panelists achieved complete consensus (i.e. mean score 5) in 64 of 86 statements (75\%), which improved to $71(82 \%)$ in the fourth round (Table 2).

Categories including the highest proportion of statements achieving excellent internal reliability (i.e. Cronbach's $\alpha$ value $>0.7$ ) in the final round were colon distension, scan parameters, use of intravenous contrast medium, general guidelines on patient preparation, role of CAD and lesion measurement.

Lower internal reliability was achieved for statements regarding the use of a rectal tube, spasmolytics, decubitus positioning and number of CT data acquisitions, faecal tagging, 2D vs. 3D reading and reporting. However, in the last round, no panellist scored their individual statements as less than 4 on the 5-point rating scale. This indicates that all panellists agreed on the statement but the level of support differed (i.e. "agree somewhat" versus "agree strongly").

\section{Discussion}

Full consensus was reached by our expert panel in $82 \%$ of the statements. In the remaining statements, full consensus was not reached but all panellists achieved a "good" level of agreement. In total, the panellists completed fours rounds; the first and second rounds served to elaborate the basic statements. The third and fourth rounds contained the core of the discussion and were necessary to reach the maximum consensus possible, so creating an optimised, homogeneous opinion for each statement.

All panellists exhibited a high level of agreement for the technical performance of CTC, with clear recommendations regarding colon distension, $\mathrm{CT}$ parameters, use of intravenous contrast agents and patient preparation. Full agreement was also reached regarding the role of CAD and lesion measurement. These data reflect a general homogeneity of approach between panel members despite their wide geographical spread. All panel members are regular tutors on the ESGAR CTC course, which may have increased their level of agreement; there is a tendency to promote a common message during panel discussions occurring during the ESGAR CTC courses $[15,16]$. Furthermore, in these areas the indexed literature is relatively mature and stable; for example available data supporting the use of automated $\mathrm{CO}^{2}$ for optimal colonic distension is relatively consistent [17-20].

However, certain aspects of practice achieved less than "full" agreement. In particular, a digital rectal examination, before insertion of the rectal tube (if rectal examination had not been performed previously), was not standard practice in many centres, but was nevertheless recommended by some panellists (with a mean score 4.56). This difference could be explained by the practice to perform a digital rectal examination before CTC amongst a few of the experts involved in the consensus. Similarly, practice differed regarding the use of intravenous spasmolytics, with many administering such agents to all patients, whereas some (in Italy) only used it in selected individuals [21, 22]. Accordingly, use of spasmolytics is recommended by the majority but is not considered mandatory.

There were minor variations in recommended CT parameters between panellists but all recommended data acquistion in at least two patient positions, without any overall preference regarding the order of acquisitions (i.e. supine or prone first). The differences in CT protocols included the need for additional CT data acquisition and insufflation in cases of poor colonic distension; a minority of experts did not consider this mandatory although they agreed it should be recommended. An additional decubitus acquisition was recommended, if required, to improve the diagnostic quality of the examination $[23,24]$. 
Although available CT technology differed among panellists, all agreed that $2.5-\mathrm{mm}$ collimation was the maximum permissible (although thinner collimation is recommended when available) and use of low radiation dose protocols is to be employed when the overriding purpose of the study is the evaluation of the colonic lumen, for example as in screening $[25,26]$. A low radiation dose should be considered a study in which the median effective dose is lower than $5.7 \mathrm{mSv}$, according to the results of the survey by Leidenbaum et al. [26]. For the staging of patients with known malignancy all the panellists agreed upon the use of standard-dose protocols and intravenous contrast medium [27, 28].

Substantial agreement was reached between panelists regarding the reading methods for interpretation of CT colonography. A combination of $2 \mathrm{D}$ and $3 \mathrm{D}$ reading was emphasised. Most of the panel were primary 2D readers but all recognised the importance of 3D integration, noting the range of different three-dimensional approaches available. The need for the reader to be adequately trained before interpreting CT colonography was emphasised and is strongly supported by the indexed literature [29-33].

Computer-aided diagnosis was acknowledged by all panellists as a potentially useful tool for CTC interpretation, if employed in a second reader paradigm. Accordingly, the use of CAD was recommended provided that readers have already undergone adequate training in general CT colonography interpretation so that they can discriminate between true- and false-positive CAD marks appropriately [34-42].

Panellists acknowledged that accurate polyp measurement is problematic for both CTC and endoscopy, with some evidence that CTC may be the superior technique $[43,44]$. Despite this advantage, it is still uncertain whether a $2 \mathrm{D}$ or a 3D measurement should be made from CT. Moreover, the accuracy of such measurements has important clinical implications for the correct classification and risk stratification of lesions, influencing subsequent recommendations for patient management [45-50]. The panel concluded that the maximal diameter of lesions should be primarily estimated using axial and MPR 2D views (which were considered to be the most reliable), avoiding a narrow CT window. Some caution should be exercised when measurements are taken using $3 \mathrm{D}$ perspectives given the potential for distortion generated by the threedimensional endoluminal rendering [51-55].

All panellists agreed that CTC should only be reported by a radiologist, and then only after adequate training [56-59]. Motivations behind this recommendation are mainly the medico-legal implications of non-radiologists reporting CTC in EU countries. In all EU countries the radiological report is definitively validated by the radiologist despite, in a few centres, a preliminary reading being performed by a radiographer. Adequate training means having interpreted a minimum amount of colonoscopy-verified cases. Although the precise number has not yet been clearly defined, the literature shows that 175 is even not sufficient for several individuals $[60,61]$.

It was acknowledged that diagnostic accuracy is lower for polyps with a maximal diameter less than $6 \mathrm{~mm}[3,4]$ but if detected with high confidence, and particularly if more than three in number, such polyps should still be reported. This contrasts with recommendations from the CT Colonography Reporting and Data System (C-RADS), authored by Zalis et al., where lesions less than $6 \mathrm{~mm}$ are considered diminutive and the recommendation is that they should not be reported [45]. The panel agreed that the patient's risk (age, family history of colorectal cancer, previous polypectomy, etc.), as well as the number of diminutive lesions detected, should be considered in the decision to report them or not.

There was little disagreement between panellists regarding the need to calibrate the laxative effect of bowel preparation/purgation to the individual patient and potential target lesion. All panellists agreed that faecal tagging should be used routinely. Different preferences for specific laxative and tagging agents were expressed (for example sodium phosphate, magnesium citrate, polyethylene glycol for cleansing, and barium, iodine or a combination of both agents for tagging), reflecting local practice [62-75].

In summary, the panel covered all important aspects regarding the practice of CTC and reached full agreement on most statements. The Consensus has been structured to give clear guidelines for the practice of $\mathrm{CT}$ colonography. The recommendations should be useful for both the radiologist who is starting a CTC service and for those who have already implemented the technique but whose practice may need updating in the light of recent developments.

Open Access This article is distributed under the terms of the Creative Commons Attribution Noncommercial License which permits any noncommercial use, distribution, and reproduction in any medium, provided the original author(s) and the source are credited.

\section{References}

1. Vining DJ, Celfand DW, Bechtold RE, Scharling ES, Grishaw EK, Shifrin RY (1994) Technical feasibility of colon imaging with helical CT and virtual reality. AJR 162:104

2. Taylor SA, Laghi A, Lefere P, Halligan S, Stoker J (2007) European Society of Gastrointestinal and Abdominal Radiology (ESGAR): consensus statement on CT colonography. Eur Radiol 17:575-579

3. Johnson CD, Chen MH, Toledano AY et al (2008) Accuracy of CT colonography for detection of large adenomas and cancers. N Engl J Med 359:1207-1217

4. Regge D, Laudi C, Galatola G et al (2009) Diagnostic accuracy of computed tomographic colonography for the detection of 
advanced neoplasia in individuals at increased risk of colorectal cancer. JAMA 17:2453-2461

5. Graser A, Stieber P, Nagel D et al (2009) Comparison of CT colonography, colonoscopy, sigmoidoscopy and faecal occult blood tests for the detection of advanced adenoma in an average risk population. Gut 58:241-248

6. Levin B, Lieberman DA, McFarland B et al (2008) American Cancer Society Colorectal Cancer Advisory Group; US MultiSociety Task Force; American College of Radiology Colon Cancer Committee. Screening and surveillance for the early detection of colorectal cancer and adenomatous polyps, 2008: a joint guideline from the American Cancer Society, the US Multi-Society Task Force on Colorectal Cancer, and the American College of Radiology. CA Cancer J Clin 58:130-160

7. McFarland EG, Fletcher JG, Pickhardt P et al (2009) American College of Radiology. ACR Colon Cancer Committee white paper: status of CT colonography 2009. J Am Coll Radiol 6:756-772

8. Mang T, Graser A, Schima W, Maier A (2007) CT colonography: techniques, indications, findings. Eur J Radiol 61:388-399

9. Yee J, Rosen MP, Blake MA (2010) ACR Appropriateness Criteria on colorectal cancer screening. J Am Coll Radiol 7:670-678

10. Cash BD (2010) Establishing a CT colonography service. Gastrointest Endosc Clin N Am 20:379-398

11. Mang T, Schima W, Brownstone E et al (2011) Consensus statement of the Austrian Society of Radiology, the Austrian Society of Gastroenterology and Hepatology and the Austrian Society of Surgery on CT colonography (Virtual Colonoscopy). Rofo 183:177-184

12. Graham B, Regehr G, Wright JG (2003) Delphi as a method to establish consensus for diagnostic criteria. J Clin Epidemiol 56:1150-1156

13. Vakil N (2011) Editorial: consensus guidelines: method or madness? Am J Gastroenterol 106:225-227

14. Cronbach LJ (1951) Coefficient alpha and the internal structure of tests. Psychometrika 16:3

15. Burling D (2010) International Collaboration for CT Colonography Standards. CT colonography standards. Clin Radiol 65:474-480

16. Boone D, Halligan S, Frost R et al (2011) CT colonography: who attends training? A survey of participants at educational workshops. Clin Radiol 66:510-516

17. Shinners TJ, Pickhardt PJ, Taylor AJ, Jones DA, Olsen CH (2006) Patient-controlled room air insufflation versus automated carbon dioxide delivery for CT colonography. AJR Am J Roentgenol 186:1491-1496

18. Burling D, Taylor SA, Halligan S et al (2006) Automated insufflation of carbon dioxide for MDCT colonography: distension and patient experience compared with manual insufflation. AJR Am J Roentgenol 186:96-103

19. Kim SY, Park SH, Choi EK et al (2008) Automated carbon dioxide insufflation for CT colonography: effectiveness of colonic distention in cancer patients with severe luminal narrowing. AJR Am J Roentgenol 190:698-706

20. Neri E, Laghi A, Regge D (2008) Re: Colonic perforation during screening $\mathrm{CT}$ colonography using automated $\mathrm{CO} 2$ insufflation in an asymptomatic adult. Abdom Imaging 33:748-749

21. Taylor SA, Halligan S, Goh V et al (2003) Optimizing colonic distention for multi-detector row CT colonography: effect of hyoscine butylbromide and rectal balloon catheter. Radiology 229:99-108

22. Rogalla P, Lembcke A, Rückert JC et al (2005) Spasmolysis at CT colonography: butyl scopolamine versus glucagon. Radiology 236:184-188

23. Gryspeerdt SS, Herman MJ, Baekelandt MA, van Holsbeeck BG, Lefere PA (2004) Supine/left decubitus scanning: a valuable alternative to supine/prone scanning in CT colonography. Eur Radiol 14:768-777

24. Buchach CM, Kim DH, Pickhardt PJ (2011) Performing an additional decubitus series at CT colonography. Abdom Imaging $36: 538-544$
25. Graser A, Wintersperger BJ, Suess C, Reiser MF, Becker CR (2006) Dose reduction and image quality in MDCT colonography using tube current modulation. AJR Am J Roentgenol 187:695701

26. Liedenbaum MH, Venema HW, Stoker J (2008) Radiation dose in CT colonography-trends in time and differences between daily practice and screening protocols. Eur Radiol 18:2222-2230

27. Filippone A, Ambrosini R, Fuschi M, Marinelli T, Genovesi D, Bonomo L (2004) Preoperative $\mathrm{T}$ and $\mathrm{N}$ staging of colorectal cancer: accuracy of contrast-enhanced multi-detector row CT colonography-initial experience. Radiology 231:83-90

28. Mainenti PP, Cirillo LC, Camera L et al (2006) Accuracy of single phase contrast enhanced multidetector CT colonography in the preoperative staging of colo-rectal cancer. Eur J Radiol 60:453459

29. Taylor SA, Halligan S, Slater A et al (2006) Polyp detection with CT colonography: primary $3 \mathrm{D}$ endoluminal analysis versus primary $2 \mathrm{D}$ transverse analysis with computer-assisted reader software. Radiology 239:759-767

30. Neri E, Vannozzi F, Vagli P, Bardine A, Bartolozzi C (2006) Time efficiency of CT colonography: $2 \mathrm{D}$ vs $3 \mathrm{D}$ visualization. Comput Med Imaging Graph 30:175-180

31. Mang T, Schaefer-Prokop C, Schima W, Maier A et al (2009) Comparison of axial, coronal, and primary $3 \mathrm{D}$ review in MDCT colonography for the detection of small polyps: a phantom study. Eur J Radiol 70:86-93

32. Mang T, Kolligs FT, Schaefer C, Reiser MF, Graser A (2011) Comparison of diagnostic accuracy and interpretation times for a standard and an advanced 3D visualisation technique in CT colonography. Eur Radiol 21:653-662

33. Lostumbo A, Wanamaker C, Tsai J, Suzuki K, Dachman AH (2010) Comparison of $2 \mathrm{D}$ and $3 \mathrm{D}$ views for evaluation of flat lesions in CT colonography. Acad Radiol 17:39-47

34. Baker ME, Bogoni L, Obuchowski NA et al (2007) Computeraided detection of colorectal polyps: can it improve sensitivity of less-experienced readers? Preliminary findings. Radiology 245:140-149

35. Taylor SA, Burling D, Roddie M et al (2008) Computer-aided detection for CT colonography: incremental benefit of observer training. Br J Radiol 81:180-186

36. Petrick N, Haider M, Summers RM et al (2008) CT colonography with computer-aided detection as a second reader: observer performance study. Radiology 246:148-156

37. Taylor SA, Charman SC, Lefere P et al (2008) CT colonography: investigation of the optimum reader paradigm by using computeraided detection software. Radiology 246:463-471

38. Regge D, Hassan C, Pickhardt PJ et al (2009) Impact of computeraided detection on the cost-effectiveness of CT colonography. Radiology 250:488-497

39. de Vries AH, Jensch S, Liedenbaum MH et al (2009) Does a computer-aided detection algorithm in a second read paradigm enhance the performance of experienced computed tomography colonography readers in a population of increased risk? Eur Radiol 19:941-950

40. Fisichella VA, Jäderling F, Horvath S et al (2009) Computer-aided detection $(\mathrm{CAD})$ as a second reader using perspective filet view at CT colonography: effect on performance of inexperienced readers. Clin Radiol 64:972-982

41. Halligan S, Mallett S, Altman DG et al (2011) Incremental benefit of computer-aided detection when used as a second and concurrent reader of CT colonographic data: multiobserver study. Radiology 258:469-476

42. Dachman AH, Obuchowski NA, Hoffmeister JW et al (2010) Effect of computer-aided detection for CT colonography in a multireader, multicase trial. Radiology 256:827-835 
43. Punwani S, Halligan S, Irving P et al (2008) Measurement of colonic polyps by radiologists and endoscopists: who is most accurate? Eur Radiol 18:874-881

44. Jeong JY, Kim MJ, Kim SS (2008) Manual and automated polyp measurement comparison of CT colonography with optical colonoscopy. Acad Radiol 15:231-239

45. Zalis ME, Barish MA, Choi JR et al (2005) Working Group on Virtual Colonoscopy. CT colonography reporting and data system: a consensus proposal. Radiology 236:3-9

46. Kim DH, Pickhardt PJ, Taylor AJ (2007) Characteristics of advanced adenomas detected at CT colonographic screening: implications for appropriate polyp size thresholds for polypectomy versus surveillance. AJR Am J Roentgenol 188:940-944

47. Pickhardt PJ, Hassan C, Laghi A et al (2008) Clinical management of small (6- to 9-mm) polyps detected at screening CT colonography: a cost-effectiveness analysis. AJR Am J Roentgenol 191:1509-1516

48. Shah JP, Hynan LS, Rockey DC (2009) Management of small polyps detected by screening CT colonography: patient and physician preferences. Am J Med 122:687-689

49. Heresbach D, Chauvin P, Hess-Migliorretti A, Riou F, Grolier J, Josselin JM (2010) Cost-effectiveness of colorectal cancer screening with computed tomography colonography according to a polyp size threshold for polypectomy. Eur J Gastroenterol Hepatol 22:716-723

50. Neri E, Faggioni L, Vagli P et al (2011) Patients' preferences about follow-up of medium size polyps detected at screening CT colonography. Abdom Imaging 36:713-717

51. Pickhardt PJ, Lee AD, McFarland EG, Taylor AJ (2005) Linear polyp measurement at $\mathrm{CT}$ colonography: in vitro and in vivo comparison of two-dimensional and three-dimensional displays. Radiology 236:872-878

52. Burling D, Halligan S, Altman DG et al (2006) Polyp measurement and size categorisation by CT colonography: effect of observer experience in a multi-centre setting. Eur Radiol 16:17371744

53. Park SH, Choi EK, Lee SS et al (2007) Polyp measurement reliability, accuracy, and discrepancy: optical colonoscopy versus CT colonography with pig colonic specimens. Radiology 244:157-164

54. Park SH, Choi EK, Lee SS et al (2008) Linear polyp measurement at $\mathrm{CT}$ colonography: 3D endoluminal measurement with optimized surface-rendering threshold value and automated measurement. Radiology 246:157-167

55. Bethea E, Nwawka OK, Dachman AH (2009) Comparison of polyp size and volume at CT colonography: implications for follow-up CT colonography. AJR Am J Roentgenol 193:1561-1567

56. Pickhardt PJ (2009) Editorial: CTC interpretation by gastroenterologists: feasible but largely impractical, undesirable, and misguided. Am J Gastroenterol 104:2932-2934

57. Carpenter S (2010) Gastroenterologists should read CT colonography. Gastrointest Endosc Clin N Am 20:271-277

58. Kim DH, Pickhardt PJ (2010) Radiologists should read CT colonography. Gastrointest Endosc Clin N Am 20:259-69

59. Fletcher JG, Chen MH, Herman BA et al (2010) Can radiologist training and testing ensure high performance in CT colonography?
Lessons From the National CT Colonography Trial. AJR Am J Roentgenol 195:117-125

60. Heresbach D, Djabbari M, Riou F et al (2011) Accuracy of computed tomographic colonography in a nationwide multicentre trial, and its relation to radiologist expertise. Gut 60:658-665

61. Liedenbaum MH, Bipat S, Bossuyt PM et al (2011) Evaluation of a standardized CT colonography training program for novice readers. Radiology 258:477-487

62. Lefere PA, Gryspeerdt SS, Dewyspelaere J, Baekelandt M, Van Holsbeeck BG (2002) Dietary fecal tagging as a cleansing method before CT colonography: initial results polyp detection and patient acceptance. Radiology 224:393-403

63. Iannaccone R, Laghi A, Catalano C et al (2004) Computed tomographic colonography without cathartic preparation for the detection of colorectal polyps. Gastroenterology 127:1300-1311

64. Gryspeerdt S, Lefere P, Herman M et al (2005) CT colonography with fecal tagging after incomplete colonoscopy. Eur Radiol 15:1192-1202

65. Lefere P, Gryspeerdt S, Marrannes J, Baekelandt M, Van Holsbeeck B (2005) CT colonography after fecal tagging with a reduced cathartic cleansing and a reduced volume of barium. AJR Am J Roentgenol 184:1836-1842

66. Zalis ME, Perumpillichira JJ, Magee C, Kohlberg G, Hahn PF (2006) Tagging-based, electronically cleansed CT colonography: evaluation of patient comfort and image readability. Radiology 239:149-159

67. Taylor SA, Slater A, Burling DN et al (2008) CT colonography: optimisation, diagnostic performance and patient acceptability of reduced-laxative regimens using barium-based faecal tagging. Eur Radiol 18:32-42

68. Slater A, Planner A, Bungay HK, Bose P, Milburn S (2009) Threeday regimen improves faecal tagging for minimal preparation $\mathrm{CT}$ examination of the colon. Br J Radiol 82:545-548

69. Neri E, Turini F, Cerri F, Vagli P, Bartolozzi C (2009) CT colonography: same-day tagging regimen with iodixanol and reduced cathartic preparation. Abdom Imaging 34:642-647

70. Liedenbaum MH, de Vries AH, Gouw CI et al (2010) CT colonography with minimal bowel preparation: evaluation of tagging quality, patient acceptance and diagnostic accuracy in two iodine-based preparation schemes. Eur Radiol 20:367-376

71. Campanella D, Morra L, Delsanto S et al (2010) Comparison of three different iodine-based bowel regimens for CT colonography. Eur Radiol 20:348-358

72. Zueco Zueco C, Sobrido Sampedro C, Corroto JD, Rodriguez Fernández P, Fontanillo Fontanillo M (2012) CT colonography without cathartic preparation: positive predictive value and patient experience in clinical practice. Eur Radiol 22:1195-204

73. Liedenbaum MH, Denters MJ, de Vries AH et al (2010) Low-fiber diet in limited bowel preparation for CT colonography: Influence on image quality and patient acceptance. AJR Am J Roentgenol 195:31-37

74. Davis W, Nisbet P, Hare C, Cooke P, Taylor SA (2011) Nonlaxative CT colonography with barium-based faecal tagging: is additional phosphate enema beneficial and well tolerated? $\mathrm{Br} \mathrm{J}$ Radiol 84:120-125

75. Liedenbaum MH, Denters MJ, Zijta FM et al (2011) Reducing the oral contrast dose in CT colonography: evaluation of faecal tagging quality and patient acceptance. Clin Radiol 66:30-37 